\title{
What About Me?: The Struggle for Identity in a Market-Based Society
}

\author{
Jee Hyun Ha \\ Department of Psychiatry, School of Medicine, Konkuk University, Seoul, Korea
}

\section{우리는 어떻게 괴물이 되어 가는가}

하 지 현

건국대학교 의학전문대학원 정신건강의학교실

저 자: Paul Verhaeghe

출판사: Scribe Publications

출간연도: 2014 (ISBN: 978-1922247377)

\section{정신분석이 사회로 눈을 돌린 이유: 우리는 어떻게 괴물이 되어 가는가}

전통적으로 정신분석이란 세상에는 별 관심이 없는 학문 이자 치료법이다. 의학적 관점에서 보자면 위암에 걸린 사람 이 부자이건 빈자이건, 공산주의자건 자본가이건, 살인범이 건 성직자이건 상관없이 차별 없이 치료를 하는 것이 원칙이 고, 치료방침도 다르지 않다. 정신분석이나 다른 상담기법들 도 마찬가지다. 환자의 인생을 깊이 이해하기 위해 사회문화 적 배경에 대한 정보는 분명히 필요하다. 그러나, 그것이 환 자의 치료에 큰 영향을 주지는 않는다고 믿는다. 한국과 미 국의 환자를 정신분석을 하는 원칙이 결국은 같다고 생각한 다. 오이디푸스 콤플렉스는 보편적 인간 심리이듯이 인간은 어느 나라 어느 시기에 살건 본질적으로는 같다는 가정을 갖는다. 시간이 흐르면서 정신분석은 진료실 안으로 들어가 서 치료를 필요로 하는 사람 그 자체에 더 깊이 파고들어 갔 다. 정신분석학이란 학문의 발전은 초기 프로이트의 정동-

Address for correspondence: Jee Hyun Ha, MD

Department of Psychiatry, School of Medicine, Konkuk University, 120-1 Neungdong-ro, Gwangjin-gu, Seoul 05030, Korea

Tel: +82-2-2030-7569, Fax: +82-2-2030-7748

E-mail: jhnha@kuh.ac.kr

This is an Open Access article distributed under the terms of the Creative Commons Attribution Non-Commercial License (http://creativecommons.org/licenses/by-nc/3.0) which permits unrestricted non-commercial use, distribution, and reproduction in any medium, provided the original work is properly cited.
트라우마 이론에서 자아심리학으로 발전하고, 이어 클라인 을 포함한 대상관계 이론, 코훗의 자기심리학을 지나 1970 년대 이후 상호주관성 이론으로까지 발전했지만 여기에 사 회적 변화는 반영된 바가 별로 없었다. 최소한 겉으로는 그 렇다는 것이다.

이런 흐름이 미흡하다고 정신분석가들 중 상당수가 생각 하기 시작했다. 수십 년 전에는 볼 수 없었던 새로운 유형의 환자들이 등장하였기 때문이다. 예를 들면 이렇다.

남자 네 명이 중년 남성 한 명을 테이프로 나무 판에 싸맨 후 얼굴에 낙서를 하고, 다른 남성은 자기 성기를 그의 얼굴 에 들이대는 치욕스러운 장면을 카메라로 담았다. 이 사건은 범죄자 집단에서 일어난 것이 아니라, 유럽의 한 마을의 회 사의 노조 대표가 다른 직원을 괴롭히는 장면이었다. 도대체 어떻게 평범한 시민이자, 직장인, 그것도 노동조합의 대표가 저런 가학적인 장면을 집단으로 저지르고 그걸 또 카메라에 담을 수 있는 것일까.

여기에 대해서 의문을 가진 정신분석가가 있었다. 벨기에 헨트 대학의 파울 페르하에허(Paul Verhaeghe)다. 그는 일찍 이 정신분석가이면서도 다양한 분야에 관심을 가져서 2000 년부터는 신경과학과 정신분석학을 연결하는 연구를 하기도 했다. 그가 신자유주의가 득세한 서구사회에 만연하기 시작 한 새로운 인격유형에 대한 심도 있는 고찰을 해낸 책 '우리 는 어떻게 괴물이 되어 가는가(What About Me?: The Struggle for Identity in a Market-Based Society)'를 썼다.

위의 사례는 그가 책의 서문에 소개한 내용이다. 우리나라 에서도 얼마 전 한 교수가 자신의 제자에게 오랜 기간 구타 를 하고, 모욕을 하고, 급기야 인분을 먹이는 만행을 저지르 다 구속되어 징역형을 선고받은 사건이 있었다. 사회적으로 존경받는 위치에 있는 사람이 어떻게 저런 인간이 인간에게 
할 것이라고는 상상하기조차 힘든 행위를 몇 년에 걸쳐 반 복적으로 저질렀을까. 더욱이 그에 동조한 다른 대학원생들 은 죄의식없이 그 행동에 동참을 해 왔다가 함께 처벌을 받 게 되었다는 것이 놀라운 일이었다. 동료의식이나 최소한의 연민, 미안함, 그래서는 안 되겠다는 양심이 작동하지 않았던 것이다. 다른 영역에서는 착한 아들, 온순한 학생이자 애인 으로 살아온 사람이었을 것이다. 초자아의 분절이 일어난 기 제는 도저히 무엇일까? 원래 사이코패스적 유형의 사람이 그걸 가장하고 살았던 것인가? 아니면 강한 본능을 억제하 던 것이 해제된 것일까.

여기에 대해서 페르하에허는 모든 것을 개인을 중심으로 보는 심리학, 정신분석학의 관점에서 과감히 벗어나서 거시 적인 사회의 변화를 주목해 봐야만 이 의문을 풀 실마리가 보인다고 주장한다. 시대와 사회의 변화에 의해 '내가 누구 인가'를 규정하는 정체성 형성과정에 큰 변화가 발생했는데 그것은 인간의 내면에 있지 않고, 정체성의 거울로 이용되는 외부세계의 변화로 인한 것이다. 정체성은 외부 세계가 우리 의 몸에 새겨 넣은 관념의 집합이고 세계의 변화로 인해 우 리의 정체성은 변할 수 있기 때문이다.

이 부분을 근대사회부터 현대까지 이어지는 역사적 맥락 에서 바라본다. 현대사회를 주도하는 사고체계인 신자유주 의는 길게 돌이켜 보면 막스 베버의 프로테스탄트 윤리와 기 독교 철학에서 비롯했다. 기독교 철학은 신아래 존재하는 인 간의 부족함과 죄의식을 기본바탕으로 하여 이를 벗어나 구 원을 얻기 위해 노력을 해야 하는 것을 강조한다. 그렇기에 인간은 경외하는 신을 믿으며 거기에 추호의 의문을 가져서 도 안 된다. 또 성실하고 근면하게 노동을 하며 금욕을 실천 해야 한다. 이는 능력주의로 발전해서 실패와 가난은 그 사람 의 존재론적 못남을 뜻하고, 인성이 유약하다고 보는 방향이 된다. 그들은 자신의 상황을 바꾸기에는 너무 게으르고 우매 한 개체인 것이다. 이에 반해 충분한 노력을 통한 성공과 부 의 축적은 모든 것이 결국 그의 노력의 결과물이므로 이 철 학에 기반하면 인성도 훌륭한 사람이라 판단하게 된다. 어느 새 재정적 권력이 도덕적 권력과 등가가 되며 사회의 지배 역시 은행가나 기업체의 지배자가 도맡는다. 실패를 게으름 의 결과이며 그 책임도 개인에게 있다고 본다. 그게 아니라 면 그 개인은 능력이 원래 모자라게 태어난 존재일 뿐이라 고 보는 사회로 진행되었다는 것이다.

이런 변화로 인해 세상은 나쁜 방향으로 더 나아가게 되 었다. 탐욕과 비도덕적 행동이 조장되고 돈을 버는 것으로 인간의 능력을 단순하게 평가하는 사회가 되었다. 이를 저자 는 '엔론사회'라고 말하면서 이런 흐름이 기업뿐 아니라 대 학, 병원과 같은 공간까지도 모두 침투하여 지배하고 있다고
비판한다. 대학도 돈을 벌기 위한 기술을 습득하는 곳으로 한정되고, 기업에 복속되며, 연구비에 교수들은 종속된다. 병원도 환자를 돈으로 환산해서 보며 고전적 의사-환자 관 계는 점차 소멸되는데 누구도 거기에 대해서 저항하지 못한 다. 의사나 환자 모두 이 신자유주의적 세계관에 흠빽 빠져 있으면서 그게 무엇인지도 모른 채 숨을 쉬고 있기 때문이 다. 이런 변화의 결과로 20세기 후반 들어 자본주의 사회일 수록 자해와 섭식장애, 우울증, 인격장애가 급증하였다. 그 러나, 이런 변화의 사회적 맥락의 원인을 찾기보다 현상을 찾아내서 그 현상을 신자유주의가 정해 놓은 규범 안으로 다 시 욱여넣는 것을 목적으로 하는 것이 정신과에서 하는 치 료, 정신치료나 정신분석이 되어 버렸다고 비판한다. 덕분에 병원과 심리치료기관에는 환자가 범람을 하게 되며 심리적 장애가 일종의 유행이 되어 버렸다. 더욱 이 모든 문제의 해 결도 결국 개인의 정신의 구조적 변화를 통해서만 가능한, 개인의 결함 내지는 결핍의 문제로 치환해 버렸다.

저자는 이런 분석에 대해 뾰족한 해결책을 제시하지는 않 았다. 그보다 개인의 문제가 아니라 사회의 큰 변화의 흐름의 결과가 우리 인간의 정체성을 규정하고 있고, 이것이 한쪽 일 부에서는 적응을 제대로 하지 못해 심하게 공격적이거나, 타 인에 대한 어떤 죄책감도 느끼지 않고, 오직 자기 중심적으로 돈과 권력, 성공에 대한 집착만 있는 새로운 유형의 인간들이 사회에 주도적 위치를 차지하는 상황이 되는 원인을 거시적으 로 잘 규명해 냈다. 일단 여기서부터 시작하는 것이다. 그는 다 시 윤리의 관점으로 돌아가자 제시하고, 인간의 조건을 끌어 안는 그리스 철학부터 시작한 전통적 방법, 이기심과 구분하 는 자기배려에 대한 비중, 일하는 사람의 권한을 지배자의 권 력과 구분하고 인정하기, 결핍을 의미로 바꾸기 위한 창의적 노력에 대한 집중이 지금의 신자유주의적 시스템에서 인간 의 존엄성과 인간본성을 회복할 최선의 길이라고 역설했다.

현대사회의 여러 병리적 현상을 경쟁에서 견뎌내지 못하 는 약한 개체의 문제이며, 결국 문제의 해결도 개인이 해야 하는 것이라고 보는 관점에 대해서 저자는 철저히 반대한다. 그리스철학과 기독교철학의 경쟁의 구도란 2천 년에 걸친 역 사적 통찰을 기반으로 뇌과학, 정신분석, 사회학, 윤리학, 철 학까지 종횡무진으로 엮어서 조목조목 논증해 냈다. 그렇기 에 저자의 지적 서사는 한 번에 읽어 내려가기 어려운 것은 사실이다. 그러나 개인과 사회의 관계, 요즘 들어 진료실에서 뭐라 단 번에 진단하기 어려운 복합적 문제를 가진 환자들 을 보고, 아임상 수준의 자기애적 문제, 충동조절의 어려움, 공격성이나 자해의 문제를 가진 환자들의 방문이 잦아지고 있다고 여기는 치료자라면 거시적 관점을 갖기 위해 한 번 읽어 볼만한 책이라 생각한다. 